\title{
Ekologi Mangrove Di Pesisir Kecamatan Tongas Dan Sumberasih Kabupaten Probolinggo, Jawa Timur
}

\author{
Dyah Wijaya*, Suryono, Nirwani Soenardjo \\ Departemen IImu Kelautan, Fakultas Perikanan dan IImu Kelautan, Universitas Diponegoro \\ JI. Prof. H. Soedarto S.H, Tembalang,Semarang, Jawa Tengah 50275 Indonesia \\ ${ }^{*}$ Corresponding author, e-mail: dyahwijaya197@gmail.com
}

\begin{abstract}
ABSTRAK : Komunitas mangrove menempati area diantara darat dan laut yang memiliki kondisi lingkungan berbeda satu sama lain. Tujuan penelitian ini untuk mengetahui struktur vegetasi mangrove dan mengetahui kesesuaian jenis mangrove yang sesuai untuk perencanaan program rehabilitasi mangrove di Desa Bayeman Kecamatan Tongas dan Desa Pesisir Kecamatan Sumberasih Kabupaten Probolinggo. Penelitian dilakukan pada Bulan Maret 2015 sampai Januari 2016. Pengambilan data vegetasi dilakukan dengan metode purposive sampling dan setiap transek dibuat plot sampling. Setiap individu pohon (plot $10 \mathrm{~m} \times 10 \mathrm{~m}$ ) dan sapling (anakan) (subplot $5 \mathrm{~m} \times 5$ $\mathrm{m})$ diidentifikasi dan diukur diameternya setinggi dada $( \pm 1,3 \mathrm{~m})$. Sementara seedling (semai) dihitung jumlah masing-masing spesies dan persentase penutupannya (subplot $1 \mathrm{~m} \times 1 \mathrm{~m}$ ). Hasil penelitian di Desa Bayeman ditemukan 7 spesies mangrove dan 1 jenis spesies di Desa Pesisir. Vegetasi pohon mangrove di Desa Bayeman dan Desa Pesisir berada dalam kondisi baik. Vegetasi Mangrove di Desa Bayeman didominasi spesies Xylocarpus mollucensis dan untuk Desa Pesisir adalah Avicennia marina.
\end{abstract}

Kata kunci: Mangrove, Kerapatan, dan Rehabilitasi

\section{Study of Mangrove Rehabilitation In Bayeman Village District And Tongas Village Source Source District Probolinggo}

\begin{abstract}
Vegetation mangrove occupy the area between land and sea that have environmental conditions differ from one another. The purpose of this studied to know about the structure and composition of mangrove vegetation for rehabilitation program planning in Bayeman Sub-District of. Tongas and Pesisir Sub-Districk Sumberasih, District of Probolinggo, East Java. The studied was conducted in March, 2015 to January, 2016. Vegetation data was done with purposive sampling method and every transect was made with plot sampling method. Each tree (plot $10 \mathrm{~m} \times 10 \mathrm{~m}$ ) and sapling (subplot $5 \mathrm{~m} \times 5 \mathrm{~m}$ ) was identified and measured on diameter at breast height $( \pm 1.3 \mathrm{~m}$ ). Meanwhile, Seedling calculated the amount of each species and the percentage of cover (subplot 1 $m \times 1 \mathrm{~m}$ ). The research finding at Bayeman shows that there are seven mangroves and one mangrove shows in Pesisir. The mangrove vegetation at Bayeman and Pesisir in good conditions. Mangrove vegetation at Bayeman is dominated by Xylocarpus mollucensis and Mangrove vegetation at Pesisir is dominated Avicennia marina .
\end{abstract}

Keywords : Mangrove, Density, and Rehabilitation

\section{PENDAHULUAN}

Mangrove merupakan sebutan umum untuk menggambarkan varietas komunitas pantai tropis yang didominasi oleh beberapa jenis pohon dan semak. Tumbuhan ini beradaptasi pada perairan asin. Ekosistem ini secara teratur hidupnya tergenang dan dipengaruhi oleh pasang surut air laut (Nybakken, 1988).

Peranan dan fungsi mangrove yang sangat penting diiringi dengan meningkatnya kegiatan pemanfaatan yang merusak disertai dengan penurunan luasan mangrove sudah selayaknya dilakukan upaya perbaikan kondisi maupun pemeliharaan ekosistem mangrove. Salah satu upaya perbaikan adalah merehabilitasi ekosistem mangrove. Rehabilitasi terdiri dari berbagai macam kegiatan, termasuk didalamnya restorasi dan penciptaan kembali habitat baru dari sistem yang 
telah menurun fungsinya menjadi stabil kembali (Stevenson et al.,1999). Program rehabilitasi telah banyak dilakukan baik oleh dinas terkait maupun lembaga sosial masyarakat yang didukung oleh masayarakat sekitar. Namun sayangnya rehabilitasi mangrove seringkali hanya dengan kegiatan penanaman kembali bibit mangrove tanpa monitoring ataupun evaluasi dari keberhasilan penanaman pada tingkat ekosistem (Field, 1996).

Kerusakan ekosistem hutan mangrove adalah perubahan fisik biotik maupun abiotik didalam ekosistem hutan mangrove menjadi tidak utuh lagi atau rusak yang disebabkan oleh faktor alam dan faktor manusia. Pada umumnya kerusakan ekosistem hutan mangrove disebabkan oleh aktivitas manusia dalam penyalah gunaan sumber daya alam di wilayah pantai tidak memperhatikan kelestarian, seperti penebangan untuk keperluan kayu bakar yang berlebihan, tambak, permukiman, industri dan pertambangan (Permenhut, 2004).

Apabila dilihat luas hutan mangrove dari tahun 2010 dan 2011, luas hutan mangrove di Kota Probolinggo mengalami penurunan dari angka 146,3 ha pada tahun 2010 menjadi 125,5 ha pada tahun 2011. Untuk lahan mangrove di Bayeman seluas 1,82 ha telah mengalami kerusakan yang disebabkan oleh aktivitas pembangunan alih fungsi lahan menjadi area tambak. Sedangkan untuk lahan mangrove di Desa Pesisir telah mengalami kerusakan seluas 3,66 ha yang disebabkan oleh abrasi pantai dan aktivitas alih fungsi lahan menjadi area penambangan pasir.

Tujuan dari penelitian ini adalah untuk Mengetahui struktur vegetasi mangrove dan Mengetahui kesesuaian jenis mangrove yang sesuai untuk program rehabilitasi mangrove di Desa Bayeman dan di Desa Pesisir Kabupaten Probolinggo. Hasil penelitian juga diharapkan dapat memberikan informasi mengenai kondisi vegetasi mangrove dan spesies mangrove yang dapat digunakan untuk rehabilitasi mangrove di Desa Bayeman dan di Desa Pesisir Kabupaten Probolinggo, Jawa Timur sehingga nantinya dapat digunakan sebagai pedoman bagi pihak yang berkepentingan dalam melakukan program rehabilitasi mangrove di kawasan tersebut.

\section{MATERI DAN METODE}

Metode pada penelitian ini menggunakan metode dekskriptif eksploratif. Menurut Nazir (2005), penelitian diskriptif adalah penelitian yang bertujuan untuk menggambarkan suatu keadaan didaerah tertentu. Sedangkan menurut Moeleong (2002), metode diskriptif eksploratif adalah metode yang dilakukan dengan cara mengumpulkan data dari hasil wawancara, catatan lapangan, foto, dokumen pribadi, dokumen resmi, ataupun data lainnya yang dapat dijadikan petunjuk untuk mencari data dengan interprestasi yang tepat menggambarkan kondisi lapangat saat ini.

Pengambilan sampel dilakukan dengan metode purposive sampling. Pengambilan data vegetasi mangrove dengan menggunakan plot, dimana Plot $10 \mathrm{~m} \times 10 \mathrm{~m}$ di dalamnya dibuat subplot $5 \mathrm{~m} \times 5 \mathrm{~m}$ dan di dalam subplot $5 \mathrm{~m} \times 5 \mathrm{~m}$ dibuat subplot $1 \mathrm{~m} \times 1 \mathrm{~m}$ yang posisinya pada masing-masing plot sudah ditetapkan pada sudut yang sama untuk mendapatkan sampel yang random/acak. Kerapatan adalah jumlah individu per unit area Mueller et.al (1974). Kerapatan relatif merupakan persentase kerapatan masing-masing jenis dalam transek Mueller et.al (1974).

Basal area merupakan hasil dari pengukuran batang pohon secara melintang Mueller et.al (1974). Semakin besar diameter batang suatu pohon maka diasumsikan bahwa semakin besar pula penutupan area oleh kanopi pohon yang ditentukan dalam perhitungan Dominansi Relatif (DR). Diameter batang tiap jenis tersebut kemudian diubah menjadi basal area.Dominansi relatif merupakan persentase penutupan suatu jenis terhadap suatu areal mangrove yang didapatkan dari nilai basal area untuk kategori pohon (Mueller et.al (1974), dengan menggunakan rumus :

$$
D R=\frac{B A i}{B A} \times 100 \%
$$

Dimana $: \mathrm{DR}=$ Dominansi Relatif; Bai $=$ Total basal area tiap spesies I; $\mathrm{BA}=$ Basal area dari semua spesies

\section{Indeks Nilai Penting (INP)}

Nilai penting diperoleh untuk mengetahui jenis yang mendominansi suatu areal mangrove. Nilai penting ini didapat dengan menjumlahkan nilai Kerapatan Relatif (KR) dan Dominansi Relatif (ĐR) 


$$
\mathrm{NP}=\mathrm{KR}+\mathrm{DR}
$$

Dimana : NP = Nilai Penting; KR = Kerapatan Relatif; DR = Dominansi Relatif

\section{Indeks Keanekaragaman (H')}

Indeks keanekaragaman merupakan karakteristik dari suatu komunitas yang menggambarkan tingkat keanekaragaman spesies dari organisme yang terdapat dalam komunitas tersebut (Odum, 1993). Dalam penelitian ini digunakan indeks keanekaragaman Shannon-Wienner (Odum, 1993), dengan rumus :

$$
H^{\prime}=-\Sigma(p i)(\log 2 \mathrm{pi})
$$

Dimana : H' = Indeks keanekaragaman Shannon- Wienner; $\mathrm{N}=$ Jumlah total spesies; $\mathrm{Ni}=$ Jumlah indvidu tiap spesies ke-l; $\mathrm{Pi}=$ Proporsi jumlah individu spesies ke-i (ni) terhadap total individu (N) : $(\mathrm{ni} / \mathrm{N})$

Untuk nilai $H^{\prime}<2,303$ berarti keanekaragaman rendah, nilai $H^{\prime} 2,303-6,908$ berarti tingkat keanekaragaman sedang, dan nilai H'>6,908 berarti tingkat keanekaragaman tinggi.

\section{Indeks Keseragaman (J')}

Indeks Keseragaman spesies merupakan perbandingan antara nilai keanekaragaman dengan Ln dari jumlah spesies (Brower dan Zar, 1977). Rumus Indeks Keseragaman adalah :

$$
\mathrm{J}=\frac{H^{\prime}}{\log 2 S}
$$

Dimana : $\mathrm{J}=$ Indeks Keseragaman; $\mathrm{H}^{\prime}=$ Indeks Keanekaragaman Shannon-Wienner; $\mathrm{S}=$ Jumlah spesies; Menurut Krebs (1985), Indeks Keseragaman berkisar antara 0 - 1 dimana: 0,6 - 1 : Keseragaman spesies tinggi; 0,4<J'<0,6 :Keseragaman spesies sedang; 0-0,4 : Keseragaman spesies rendah

\section{Analisa Ukuran Butir dan Bahan Organik Sedimen}

Segitiga Shepard yang digunakan dalam klasifikasi jenis sedimen merupakan pembagian atas tiga jenis sedimen, yaitu pasir, lanau, dan lempung. Metode segitiga Shephard lebih sesuai digunakan untuk klasifikasi pada sampel dengan ukuran butiran yang cenderung kecil dibandingkan dengan metode segitiga Folk.

Penentuan kategori kandungan bahan organik didasarkan pada Landon (1991), dimana kandungan bahan organik $\square 2 \%$ : sangat rendah; $2,1 \%$ - 4\%: rendah; $4,1 \%$ - $10 \%$ : sedang; $10,1 \%$ - 20\%: Tinggi; > 20\%: sangat tinggi. Untuk analisa kandungan bahan organik dilakukan dengan metode Loss on Ignition (LOI). Adapun tahapan analisis kandungan bahan organik menggunakan metode LOI berdasarkan prosedur laboratorium Universitas of Pittsburg dan ketetapan Allen et.al (1974) sebagai berikut :

$$
\mathrm{Li}=\frac{\mathrm{Wo}-\mathrm{Wt}}{\mathrm{Wo}} \times 100 \%
$$

Dimana : $\mathrm{Li}=$ loss on ignation $(\mathrm{LOI}) ;$ Wo = berat awal $(\mathrm{gram}) ; \mathrm{t}=$ berat akhir $(\mathrm{gram})$

\section{Analisa Kesesuaian Lahan}

Klasifikasi tingkat kerusakan mangrove dilakukan dengan menyesuaikan tingkat kerapatan mangrove yang diperoleh dengan baku mutu kriteria kerusakan ekosistem mangrove. Dalam penelitian ini setiap nilai kerapatan dibagi dalam tiga kriteria yaitu, baik (sangat padat), sedang dan rusak (sangat jarang).

Tabel 1. Baku Mutu Kriteria Tingkat Kerusakan Mangrove Menurut Keputusan Menteri Lingkungan Hidup No.201 Tahun 2004

\begin{tabular}{cccc}
\hline Kriteria Tingkat Kerusakan & Penutupan (\%) & Kerapatan (ind/ha) \\
\hline Baik & Sangat Padat & $>75$ & $>1500$ \\
Rusak & Sedang & $>50-<75$ & $1000-1500$ \\
& Jarang & $<50$ & $<1000$ \\
\hline
\end{tabular}




\section{HASIL DAN PEMBAHASAN}

Hasil penelitian menunjukkan bahwa mangrove yang ditemukan di Desa Bayeman terdapat 7 jenis mangrove, dan 1 jenis mangrove ditemukan di Desa Pesisir. Kondisi lingkungan pada ekosistem mangrove di Desa Bayeman dan Desa Pesisir bisa dikatakan cukup mendukung kehidupan ekosistem mangrove. Data komposisi mangrove selengkapnya dijelaskan pada Tabel 2.

Hasil penelitian mengenai kajian rehabilitasi mangrove di Desa Bayeman Kecamatan Tongas menunjukkan bahwa area ini didominansi oleh spesies Xylocarpus mollucensis. Sedangkan di Desa Pesisir didominasi Avicennia marina. Hal ini ditunjukkan dengan tingginya Indeks Nilai Penting (INP) dan dominansinya pada kategori pertumbuhan (pohon dan semai) di areal penelitian. Kategori pohon di Desa Bayeman didominasi Xylocarpus mollucensis ditunjukkan dengan Indeks Nilai Penting (INP $=73,21 \%$ ) dengan nilai dominasi relatif $(\mathrm{DR}=49,24 \%$ ), kerapatan relatif $(K R=24,47 \%)$ dan nilai Kerapatan ( $K=2300$ ind/ha ) sedangkan di Desa Pesisir dominansi spesies Avicennia marina ditunjukkan Indeks Nilai Penting (INP $=100 \%$ ) dengan nilai dominasi relatif $(\mathrm{DR}=100 \%)$, kerapatan relatif $(K R=100 \%)$ dan memiliki nilai kerapatan ( $\mathrm{K}=2233 \mathrm{ind} / \mathrm{ha}$ ).

Kategori anakan di Desa Bayeman didominasi Xylocarpus mollucensis ditunjukkan dengan Indeks Nilai Penting (INP $=146,66 \%$ ) dengan nilai dominasi relatif $(D R=71,19 \%)$, kerapatan relatif $(K R=75,47 \%)$ dan nilai Kerapatan ( $\mathrm{K}=5333 \mathrm{ind} / \mathrm{ha})$ sedangkan $)$ sedangkan di Desa Pesisir dominansi spesies Avicennia marina ditunjukkan Indeks Nilai Penting (INP $=100 \%$ ) dengan nilai dominasi relatif $(D R=100 \%)$, kerapatan relatif $(K R=100 \%)$ dan memiliki nilai kerapatan ( $\mathrm{K}=3933 \mathrm{ind} / \mathrm{ha}$ ). Kategori semaai di Desa Bayeman didominasi Xylocarpus mollucensis ditunjukkan dengan Indeks Nilai Penting (INP $=113,24 \%$ ) dengan nilai dominasi relatif $(\mathrm{DR}=57,14 \%$ ), kerapatan relatif $(\mathrm{KR}=56,10 \%$ ) dan nilai Kerapatan ( $\mathrm{K}=136667 \mathrm{ind} / \mathrm{ha}$ ) sedangkan ) sedangkan di Desa Pesisir dominansi spesies Avicennia marina ditunjukkan Indeks Nilai Penting $(\mathrm{INP}=100 \%)$ dengan nilai dominasi relatif $(\mathrm{DR}=100 \%)$, kerapatan relatif $(\mathrm{KR}=$ $100 \%$ ) dan memiliki nilai kerapatan ( $\mathrm{K}=3133 \mathrm{ind} / \mathrm{ha}$ ).

Hasil pengukuran kualitas air dan tanah untuk melihat kesesuaian jenis mangrove terhadap kondisi lingkungan menunjukkan bahwa Desa Bayeman dan Desa Pesisir cocok untuk beberapa jenis mangrove. Setelah data parameter lingkungan di Desa Bayeman dan di Desa Pesisir dianalisis dengan cara mencocokkan data tersebut terhadap beberapa parameter lingkungan berdasarkan pustaka acuan, ditemukan beberapa jenis pohon mangrove yang sesuai dan dapat tumbuh serta dapat menjadi pilihan.

Beberapa faktor yang perlu diperhatikan dalam melakukan penanaman agar kegiatan rehabilitasi ini dapat berjalan dengan baik yaitu : (1) Meningkatkan kesadaran masyarakat akan manfaat mangrove sehingga pasca penanaman bibit mangrove masyarakat bersedia untuk

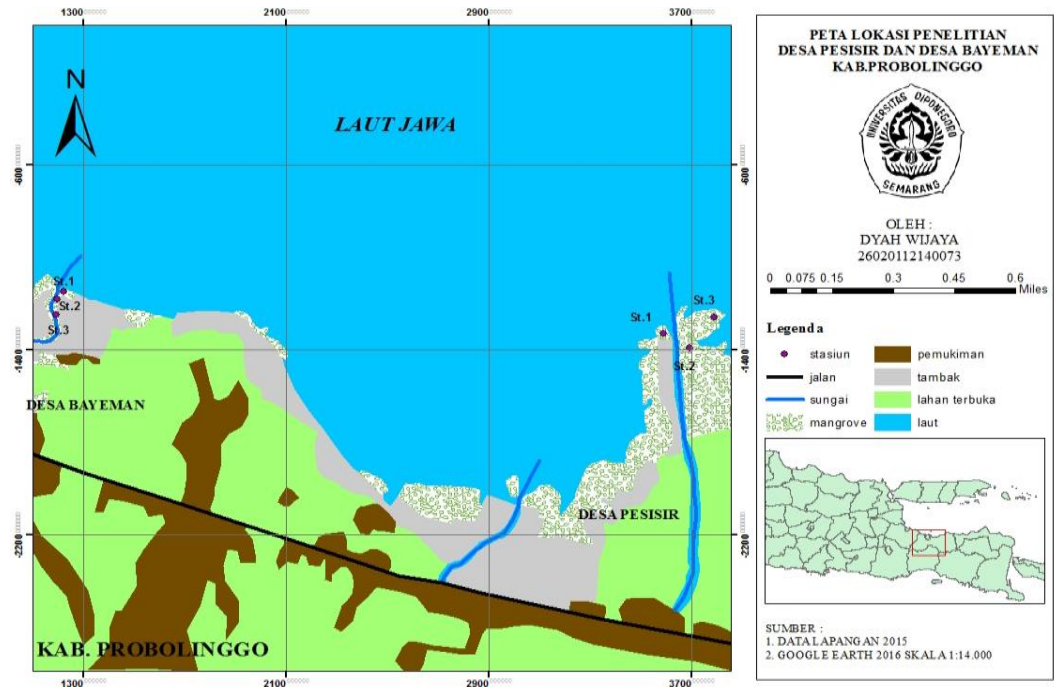

Gambar 1. Peta Lokasi Penelitian 
Tabel 2. Komposisi Jenis Mangrove Yang Ditemukan di Desa Bayeman dan di Desa Pesisir

\begin{tabular}{llc}
\hline No & Komponen Vegetasi & Spesies \\
\hline 1 & Mayor & Avicennia marina, Bruguiera gymnorrhiza, \\
& & Rhizopora mucronata, Soneratia alba \\
2 & Minor & Exocaria agallocha, Xylocarpus mollucensis, \\
& & Xylocarpus granatum \\
\hline
\end{tabular}

merawat dan melakukan penyulaman jika terdapt bibit yang mati. Dikarenakan banyak program rehabilitaswi yang gagal akibat pengelolaan pasca penanaman yang kurang baik. (2) Melihat kondisi lingkungan perairan yang akan ditanami mangrove, jika gelombang air laut kurang baik maka sebaiknya di sekitar lokai penanaman diberi APO (alat pemecah ombak) sehingga ombakyang dating tidak merusak bibit semai yang baru ditanam. (3) Mengantisipasi jenis hama pengganggu pertumbuhan bibit mangrove seperti 3W (wideng/ kepiting, wedhus/ manusia, dan wong/ manusia) dan beberapa hama lain yang ditemukan pada mangrove adalah ulat mangrove, serangga sisik (scale insect), ganggang laut, dan teritip. Menurut Dewiyanti et.al, 2013 terdapat 4 jenis hama yang menjadi penyebab kegagalan rehabilitasi mangrove di Aceh yaitu Balanus Amphitrite, Sesarma sp, Pteroma plagiophleps, dan Clibanarius sp. Dalam melakukan antisipasi pertumbuhan hama dapat dengan penyemprotan insektisida, penyiraman bibit dengan air laut, dan menggunakan obat pembasmi moluskisida (Priyono, 2010). (4) Melakukan penjarangan yaitu menebang sebagian pohon untuk memberi ruang tumbuh pohon yang lainnya khususnya bibit semai, sehingga semai yang baru ditanam mendapatkan sinar matahari yang cukup untuk proses pertumbuhan.

\section{KESIMPULAN}

Desa Bayeman ditemukan 7 jenis spesies mangrove yang didominasi oleh jenis Xylocarpus mollucensis. Desa Pesisir hanya ditemukan 1 jenis spesies yaitu Avicennia marina. Kondisi lingkungan Desa Bayeman dan Desa Pesisir Kabupaten Probolinggo mendukung untuk pertumbuhan mangrove jenis mangrove Avicennia marina, Rhizopora mucronata dengan melihat kondisi lingkungan pada kedua wilayah tersebut.

\section{DAFTAR PUSTAKA}

Allen, S.E., Grimshaw H.M., Parkinson, J.A. \& Quarmby, C.. 1974. Analysis of Soil in Chemical Analysis of Ecological Materials. Oxford, Blackwell Scientific Publication, Oxford

Brower, J.E., \& Zar, J.H. 1977. Field and Laboratory Methods for General Ecology. W. C. Browen Company Publishers, Lowa.

Field, C.D. 1996. Impacts of Expected Climate Change on Mangroves. Hydrobiologia

KKP, 2011. Laporan Akhir Identifikasi dan Perencanaan Rehabilitasi Wilayah Pesisir di Jawa Timur 2011. Surabaya

Moeleong, J.L. 2002. Metodologi Penelitian Kualitatif. PT. Remaja Rosdakarya. Bandung.

Mueller, D., \& Ellenberg, H. 1974. Aims and Methods of Vegetation Ecology. John Willey. London.

Nazir, Moh. 2005. Metode Penelitian. Jakarta: Ghalia Indonesia

Nybakken, J.W. 1998. Biologi Laut; Suatu Pendekatan Ekologis. PT. Gramedia. Jakarta.

Odum, P.E. 1993. Dasar-Dasar Ekologi. Gadjah Mada University Press. Yogyakarta.

Kementerian Kehutanan 2004. Peraturan Menteri Kehutanan tentang Pedoman Pembuatan Tanaman Rehabilitasi Hutan Mangrove Gerakan Rehabilitasi Hutan dan Lahan.

Priyono, A. 2010. Panduan Praktis Teknik Rehabilitasi Mangrove di Kawasan pesisir Indonesia. KeSEMaT. Semarang

Stevenson, N.J., Lewis, R.R. \& Burbridge, P.R.. 1999. Disused Shrimp Ponds and Mangrove Rehabilitation. In An International Perspective on Wetland Rehabilitation ( Streever, W., ed.). Kluwer Academic Publishers. 